\title{
Erratum to expanded criteria for active surveillance in prostate cancer: a review of the current data
}

\author{
Cameron Jones $^{1}$, Mina M. Fam², Benjamin J. Davies ${ }^{2}$ \\ ${ }^{1}$ University of Pittsburgh School of Medicine, Pittsburgh, PA, USA; ${ }^{2}$ Department of Urology, University of Pittsburgh Medical Center, Pittsburgh, \\ PA, USA \\ Correspondence to: Cameron Jones. 1100 Liberty Ave., Suite 507, Pittsburgh, PA 15222, USA. Email: ccj8@pitt.edu.
}

doi: $10.21037 /$ tau.2018.08.05

View this article at: http://dx.doi.org/10.21037/tau.2018.08.05

Erratum to: Transl Androl Urol 2018;7:221-7.

Expanded criteria for active surveillance in prostate cancer: a review of the current data

The article entitled "Expanded criteria for active surveillance in prostate cancer: a review of the current data" (1) published in Vol 7, No 2 of Translational Andrology and Urology included an error in the second sentence of Abstract. In that sentence, "mortality (PCSM)" should be changed to "survival".

Therefore, the correct sentence should be "Appropriately selected AS patients have a 10-year prostate cancer-specific survival approaching $99 \% . "$

We regret the error and any inconvenience it might have caused.

\section{References}

1. Jones C, Fam MM, Davies BJ. Expanded criteria for active surveillance in prostate cancer: a review of the current data. Transl Androl Urol 2018;7:221-7.

Cite this article as: Jones C, Fam MM, Davies BJ. Erratum to expanded criteria for active surveillance in prostate cancer: a review of the current data. Transl Androl Urol 2018;7(4):764. doi:10.21037/tau.2018.08.05 